\title{
Dietary Standards in the United States
}

\author{
By L. A. MAYNARD, Ph.D.
}

The dietary standards in general use by Government agencies and food and nutrition scientists throughout the United States are the recommended dietary allowances formulated by the Food and Nutrition Board of the National Research Council. These dietary allowances, revised in October 1948, are presented in the accompanying table (1).

\section{Normal Food Supply Situations}

The dietary allowances specify levels which the Food and Nutrition Board recommends as "normally desirable goals or objectives" in dietary practice. The allowances for the different nutrients are generally higher than those found in other promulgated standards because they are intended to represent not merely average requirements, but "levels enough higher to cover substantially all of the individual variations in the requirements of normal people." Many individuals would thus receive intakes above their needs, but there seems to be no way of identifying persons whose requirements are

Dr. Maynard is chairman of the Food and $\mathrm{Nu}$ trition Board, National Research Council, and director of the School of Nutrition at Cornell University, Ithaca, N. Y. This paper is based on material presented before the scientific session of the Combined Conference on Administrative and Scientific Aspects of Food in Civil Defense held in London, November 26 to Decernber 3, 1951 (see Public Health Reports, July 1952, p. 607). markedly above the average, and the board has no evidence that any individual would be harmed by consuming the full nutrient allowances specified.

All of the allowances are intended to represent intakes actually consumed. As is to be expected in the present state of our knowledge, the data represent some compromises of the views of those qualified to express an opinion with respect to a given nutrient. Nevertheless, the table as a whole has won widespread acceptance. None of the values, however, are considered final. A committee of the board is constantly examining new data as they appear and reevaluating the old, with the objective of making needed modifications. It is also reviewing previously and currently published studies to provide data for nutrients not now included in the table. The data and viewpoints set forth in the reports of the United Kingdom and of Canada, published since the last revision of the recommended dietary allowances, are among the studies being given consideration by the committee.

The experimental bases and other considerations which led to the formulation of the present recommended dietary allowances are set forth in considerable detail by the National Research Council (1). A few explanatory statements regarding certain values are given here.

\section{Calories}

In contrast to the situation with respect to nutrients, there are definite reasons why unneeded intakes of calories should be avoided by adults. It is simple to state that each person 
should consume enough calories, and no more, to maintain his ideal weight, but setting up a workable standard which will actually accomplish this for the individual is quite another matter. Age, sex, body build, genetic make-up, physical activity, and climate all have an influence on the requirements.

The board's calorie allowances take into ac-

\section{Recommended daily dietary allowances, revised $1948^{1}$}

[Food and Nutrition Board, National Research Council]

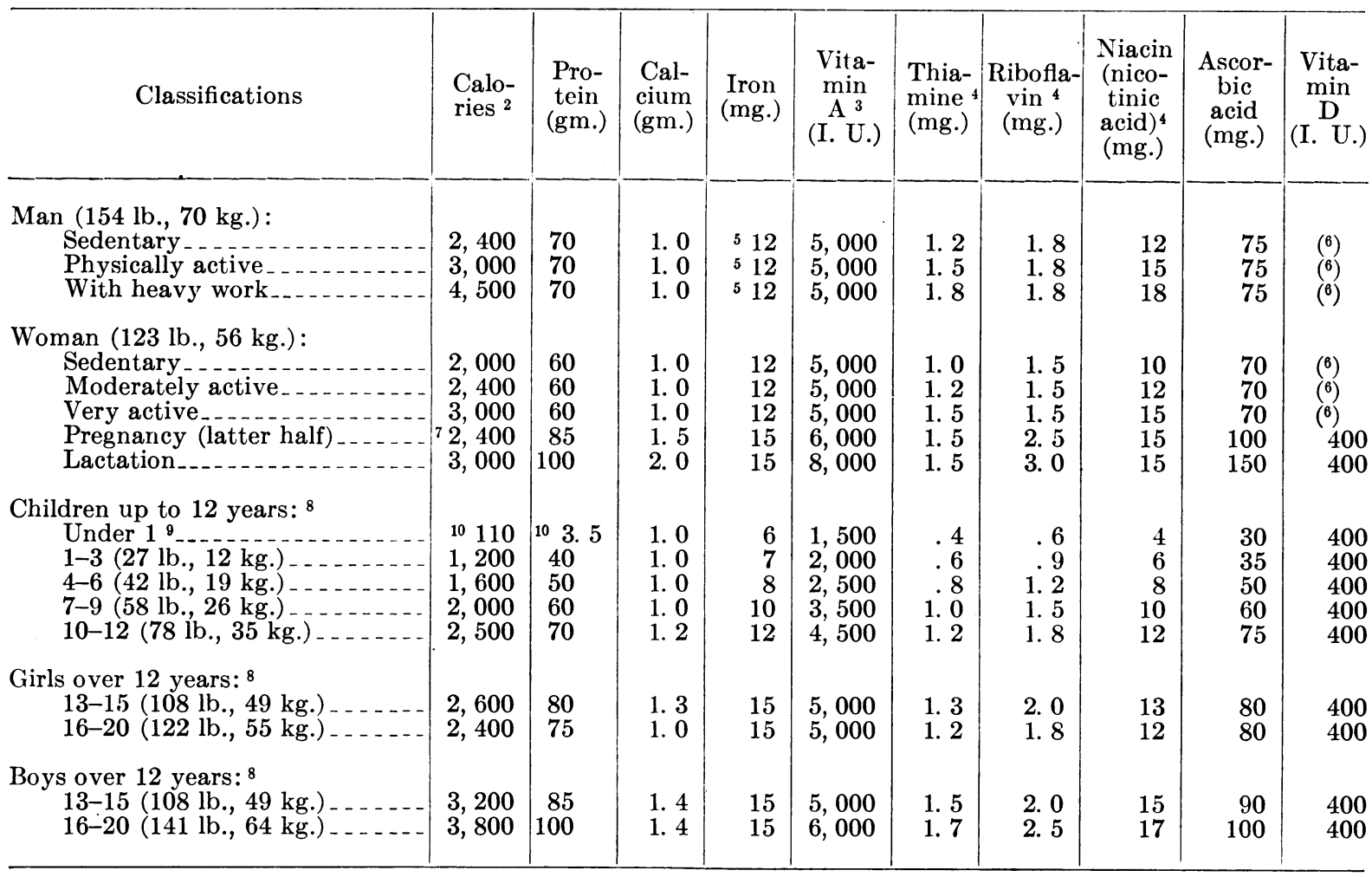

${ }^{1}$ Objectives toward which to aim in planning practical dietaries: The recommended allowances can be attained with a good variety of common foods which will also provide other minerals and vitamins for which requirements are less well known.

${ }^{2}$ Calorie allowances must be adjusted up or down to meet specific needs. The calorie values in the table are therefore not applicable to all individuals but rather represent group averages. The proper calorie allowance will maintain, over an extended period, body weight or rate of growth at the level most conducive to well-being.

${ }^{3}$ The allowance depends on the relative amounts of vitamin $\mathbf{A}$ and carotene. The allowances of the table are based on the premise that approximately twothirds of the vitamin $A$ value of the average diet in this country is contributed by carotene and that carotene has half or less than half the value of vitamin $A$.

${ }^{4}$ For adults (except pregnant and lactating women) receiving diets supplying 2,000 calories or less, such as reducing diets, the allowances of thiamine and niacin may be $1 \mathrm{mg}$. and $10 \mathrm{mg}$., respectively. The fact that figures are given for different calorie levels for thiamine and niacin does not imply that we can estimate the requirement of these factors within 500 calories, but they are added merely for simplicity of calculation. In the present revision, riboflavin allowances are based on body weight rather than calorie levels. Other members of the $B$ complex also are required, though no values can be given. Foods supplying adequate thiamine, riboflavin, and niacin will tend to supply sufficient amounts of the remaining $B$ vitamins.

'There is evidence that the male adult needs relatively little iron. The need will usually be provided for if the diet is satisfactory in other respects.

${ }^{6}$ The need for supplemental vitamin $\mathrm{D}$ by vigorous adults leading a normal life seems to be minimum. For persons working at night and for nuns and others whose habits shield them from the sunlight, as well as for elderly persons, the ingestion of small amounts of vitamin $D$ is desirable.

${ }^{7}$ During the latter part of pregnancy the calorie allowance should increase to approximately 20 percent above the preceding level. The value of 2,400 calories represents the allowance for pregnant, sedentary women.

${ }^{8}$ Allowances for children are based on the needs for the middle year in each group (as 2, 5, 8, etc.) and are for moderate activity and for average weight at the middle year of the age group.

${ }^{9}$ Needs for infants increase from month to month with size and activity. The amounts given are for approximately 6 to 8 months. The dietary requirements for some of the nutrients such as protein and calcium are less if derived largely from human milk.

${ }^{10}$ Amount required for $2.2 \mathrm{lb}$. (1 kg.) of body weight. 
count sex differences and three categories of activity. The limitations involved in the use of these three categories are fully appreciated, but they cannot be overcome simply by adding more categories. The problem remains of so defining the categories selected as to permit the classification of a population accordingly. Although data are available for caloric expenditures in various types of work, the variable expenditures of individuals during nonworking hours or at tasks not covered by their regular work seem impossible to classify. In view of the variables not taken into account in the general recommendation, the board suggests that its calorie allowances be regarded as subject to modification of plus or minus 15 to 20 percent, according to conditions.

The need for more precise statements of calorie allowances is recognized, both because they are obviously dominant factors in the total food supply needed, and also because of the deleterious effects of an excess in the adult. Committees of the board are giving active consideration to the issues involved.

\section{Calcium}

The present adult allowance of calcium is 20 percent higher than the board's previous recommendation. Data obtained in the United States reveal a wide range in the calcium intake required by adults to maintain calcium equilibrium. For some, as little as $0.3 \mathrm{mg}$. daily appears to suffice, whereas at the other extreme some individuals, particularly elderly people, seem to require even more than $1 \mathrm{gm}$. daily. Although the average need is manifestly much less than $1 \mathrm{gm}$., the board felt that this figure was in keeping with the policy of setting the allowance high enough to meet the needs of all normal individuals. Recognition was also given to the evidence from experiments with rats that liberal intakes of calcium promote longevity.

\section{Vitamin $C$}

Although the board recognizes that the physical symptoms of scurvy can be prevented and even cured by much less vitamin $\mathrm{C}$ than specified in its allowances, the accumulating evidence regarding the variety of metabolic roles which the vitamin plays and the rapid depletion of body stores during stress has indicated the desirability of maintaining a liberal supply in the blood and other tissues. The allowances have been placed accordingly.

\section{Ditamin A Value}

The content of vitamin A itself and of its precursor carotene together account for the vitamin A value of a dietary. The allowances given in the table for vitamin $\mathbf{A}$ are based on the premise that a unit of carotene has one-half the value of a unit of vitamin $\mathbf{A}$ per se and that in the average American diet two-thirds of the vitamin $\mathbf{A}$ value is supplied by carotene. The limitations and uncertainties of these bases, particularly in terms of specific foods and diets, are recognized.

\section{Emergency Food Supply Situations}

In answer to requests for suggestions which may aid State and local civil defense agencies in formulating plans for emergency feeding of uninjured civilians, the Committee on Dietary Allowances of the board has prepared a brief report. This report points out that it is unrealistic to expect to provide adequate diets or to designate specific nutritional requirements for any large population in emergencies following an atomic attack. It states that provision of foods to supply energy needs should suffice for the first few days of an emergency, especially if foods which supply protein and other nutrients, as well as calories, are selected.

According to the report, "drastic reduction of food intake for a few days, or even weeks, is tolerated reasonably well except by infants, by lactating women, by the sick and injured, and by those engaged in heavy physical work. This is particularly true if the calories that are available come largely from foods that furnish a variety of nutrients such as bread, potatoes, and milk, in contrast to foods such as sugar, syrups, and oils, which supply calories primarily." For periods of food shortage lasting longer than a few weeks, the report adds, special provision must be made for supplying foods not only for the more vulnerable groups, but also for pregnant women.

As the period of emergency is prolonged, the need for certain individual nutrients increases. 
The report states: "If the emergency feeding must be continued for more than a few weeks, the problem of individual nutrients, as well as calories, assumes importance. Cognizance must be taken of needs for protein, thiamine, other B-complex vitamins, and ascorbic acid." Deficiencies of minerals and fat soluble vitamins are not likely to occur, however, unless food shortages persist over several months.

The report stresses the importance of nutritional appraisal of the population by trained survey teams as a part of any emergency program. Such an appraisal will detect any deleterious effects of the food allowance on health and will serve as a basis for further dietary planning.

In regard to use of foods on hand during an atomic explosion, the report points out that food present in closed containers is usually safe if the outside of the container is washed. Food in open or broken containers exposed to radioactive materials should, however, be monitored before use. The report cautions against wasting food because of the possibility of contamination by atomic radiation.

The recommendations of this report, though much less detailed, are in general accord with those set forth by the Federal Civil Defense Administration (2).

\section{REFERENCES}

(1) National Research Council, Food and Nutrition Board: Recommended dietary allowances. Washington, P. C., National Research Council, 1948. Reprint and Circular Series, No. 129.

(2) U. S. Federal Civil Defense administration: Health services and special weapons defense. Washington, D. C., U. S. Government Printing Office, 1950. Manual AG-11-1, pp. 144-150.

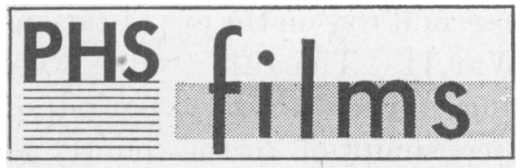

\section{Sanitary Storage and Collection of Refuse}

$16 \mathrm{~mm} .$, sound, color, 19 minutes, 1952.

Audience: Public health and sanitation personnel.

Available: Loan-Communicable Disease Center, Public Health Service, Box 185, Chamblee, Ga. Purchase-Castle Film Division, United World Films, 1445 Park Avenue, New York 29, N. Y.

Operations essential in the sanitary handling, storage, and collection of refuse from homes, restaurants, and business establishments are depicted by this film, produced by the Audio Visual Production Branch of the Communicable Disease Center, Public Health Service, in cooperation with the Public Health Service, Division of Sanitation.

The film is of particular interest to Public Health Service personnelsanitary engineers, sanitarians, and health officers-and can be used by them in working with municipal officials and local sanitation department employees. Refuse, the film points out, consists of both garbage and rubbish. Unless disposed of promptly, refuse furnishes harborage to rodents, flies, and mosquitoes. Local government agencies are encouraged to inform the individual property owner and restaurant operator how to store refuse properly to fit in with good community collection and disposal practices. Garbage may be separated from rubbish for disposal in grinders or to hog

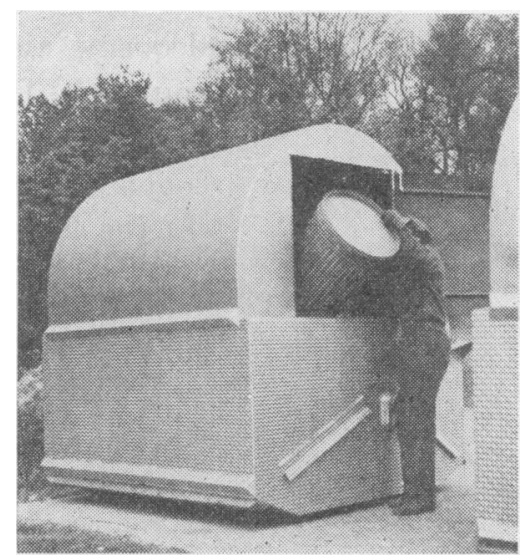

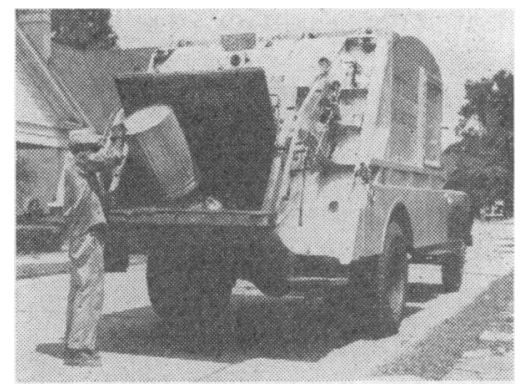

farms, or the two may be combined for disposal in sanitary land fills or in modern predrying kiln process incinerators. In either case, the individual is responsible for sanitary storage of refuse on his own premises. He should wrap all garbage and place it in heavy metal, tightlidded, conveniently located garbage cans.

The film illustrates several devices, such as cloth collection squares, to protect the citizen's cans and to make the loading of garbage into the truck easier. It emphasizes that planned collection routes, properly designed trucks, and courteous service by sanitation department employees pay off in health and efficiency. 